\title{
A evolução do Pronaf nas Regiões de Desenvolvimento (RD) de Pernambuco
}

\author{
The evolution of Pronaf in the Development Regions (DR) of Pernambuco \\ La evolución del Pronaf en las Regiones de Desarrollo (RD) de Pernambuco
}

Recebido: 20/07/2021 | Revisado: 27/07/2021 | Aceito: 29/07/2021 | Publicado: 05/08/2021

\author{
Micheli Fontes Fialho \\ ORCID: https://orcid.org/0000-0002-8677-6736 \\ Universidade Federal de Viçosa, Brasil \\ E-mail: micheli.fialho@ufv.br \\ José Ambrósio Ferreira Neto \\ ORCID: https://orcid.org/0000-0002-1173-4582 \\ Universidade Federal de Viçosa, Brasil \\ E-mail: ambrósio@ufv.br \\ Janderson Damaceno dos Reis \\ ORCID: https://orcid.org/0000-0002-7175-0496 \\ Universidade Federal de Viçosa, Brasil \\ E-mail: janderson@ufv.br
}

\begin{abstract}
Resumo
O objetivo deste artigo é analisar a evolução do Pronaf nas Regiões de Desenvolvimento (RD) de Pernambuco, no período de 2013 a 2018. O estudo, caracterizado como analítico-descritivo, embasou-se em dados secundários sobre o Pronaf obtidos no Banco Central do Brasil e a respeito das características dos estabelecimentos familiares no Censo Agropecuário de 2017. Recorreu-se também à Taxa Geométrica de Crescimento (TGC) para analisar os percentuais de incremento ou perda média anual das variáveis associadas ao Pronaf. Os resultados sinalizam leve queda no número de contratos totais do Programa e constância nos valores monetários totais. Pela perspectiva das RDs, evidenciou-se pontual crescimento e quedas significativas quanto ao número de contratos totais, em contraposição a diminuições mais expressivas, e em um quantitativo maior de Regiões, no que se refere aos valores dos contratos. Acerca das diferentes atividades financiadas, notou-se panoramas inversos para a agricultura e a pecuária, em que as quedas anuais nos contratos agrícolas foram bem mais relevantes que os aumentos verificados na pecuária. Assim, constatou-se desigualdades entre as Regiões e evidenciou-se que cerca de 50\% do crédito rural do Pronaf se concentrou em três RDs, que são também as áreas que reúnem o maior número de estabelecimentos familiares. No entanto, apresentam menores percentuais de assistência técnica, corroborando-se com a premissa de que recursos mais volumosos não têm se refletido em maiores possibilidades de suporte específico para a sua aplicação nos estabelecimentos rurais.
\end{abstract}

Palavras-chave: Agricultura familiar; Pronaf; Crédito rural; Regiões de desenvolvimento; Pernambuco.

\begin{abstract}
The aim of this article is to analyze the evolution of Pronaf in the Development Regions (DR) of Pernambuco, in the period from 2013 to 2018. The study, characterized as analytical-descriptive, was based on secondary data on Pronaf obtained from the Central Bank of Brazil and on the characteristics of family establishments in the 2017 Census of Agriculture. The Geometric Growth Rate (GGR) was also used to analyze the percentages of annual average increase or loss of variables associated with Pronaf. The results signaled a slight drop in the number of total Program contracts and consistency in the total monetary values. From the perspective of the DRs, there was a punctual growth and significant decreases in the number of total contracts, in contrast to more significant decreases, and in a greater number of Regions, considering to the values of the contracts. Regarding the different activities financed, it was observed opposite scenarios for agriculture and livestock, in which the decrease in agricultural contracts was more expressive than the increases in livestock financing. Consequently, inequalities were found between the Regions and it was evidenced that around 50\% of Pronaf rural credit was concentrated in three DRs, which are also the areas that bring together the largest number of family establishments. However, they have one of the lowest percentages of technical assistance, corroborating with the premise that more voluminous resources have not been reflected in greater possibilities of specific support for their application in rural establishments.
\end{abstract}

Keywords: Family farming; Pronaf; Farm credit; Development regions; Pernambuco.

\section{Resumen}

El propósito de este artículo es analizar la evolución del Pronaf en las Regiones de Desarrollo (RD) de Pernambuco, en el período de 2013 a 2018. El estudio, caracterizado como analítico-descriptivo, se basó en datos secundarios del Pronaf obtenidos del Banco Central de Brasil sobre las características de los establecimientos familiares en el Censo Agropecuario de 2017. También se utilizó la Tasa de Crecimiento Geométrico (TGC) para analizar los porcentajes de aumento o pérdida promedio anual de las variables asociadas al Pronaf. Los resultados indican una leve disminución en 
el número de contratos totales del Programa y una constancia en los valores monetarios totales. Desde la perspectiva de los DR, hubo crecimientos ocasionales y caídas significativas en el número de contratos totales, en contraste con caídas más expresivas, y en una mayor cantidad de Regiones, en términos de valor de los contratos. En cuanto a las distintas actividades financiadas, se observó escenarios inversos para la agricultura y la ganadería, en los que las caídas anuales en los contratos agrícolas fueron mucho más relevantes que los aumentos observados en la ganadería. Así, se encontraron desigualdades entre las Regiones y se evidenció que alrededor del $50 \%$ del crédito rural del Pronaf se concentraba en tres RD, que también son las áreas con mayor número de establecimientos familiares. Sin embargo, presentan menores porcentajes de asistencia técnica, corroborando la premisa de que recursos más voluminosos no se han reflejado en mayores posibilidades de apoyo específico para su aplicación en establecimientos rurales.

Palabras clave: Agricultura familiar; Pronaf; Crédito rural; Regiones de desarrollo; Pernambuco.

\section{Introdução}

Nas políticas agrícolas brasileiras, o crédito tem sido o principal instrumento de fomento desde as primeiras décadas do século 20 (Buanain, et al., 2014). Entretanto, até meados dos anos 1990, os estímulos fornecidos por meio do financiamento rural contemplavam somente grandes e médios produtores mais capitalizados (Aquino \& Schneider, 2015). Os pequenos agricultores, mais pobres, com baixa capacidade produtiva e dificuldades de acesso aos mercados, passaram a ser beneficiados pelas linhas de crédito apenas após a criação do Programa Nacional de Fortalecimento da Agricultura Familiar (Pronaf), em 1996, pelo Decreto $\mathrm{n}^{\mathrm{o}} 1.946$, configurando a categoria genérica dos agricultores familiares.

Apesar dos avanços com a criação do Pronaf, foi somente a partir de 2006, com a instituição da Lei $n^{\circ} 11.326$, que foram estabelecidas diretrizes para a formulação de uma Política Nacional da Agricultura Familiar e Empreendimentos Familiares Rurais. Do mesmo modo, apenas dez anos depois, em 2017, com o Decreto n ${ }^{\circ}$ 9.064, essa política foi regulamentada e requisitos de identificação e qualificação dos agricultores familiares foram definidos de forma mais objetiva, considerando área, uso da força de trabalho, gestão familiar e renda das atividades realizadas no estabelecimento rural.

Mesmo com dificuldades na estruturação, o Pronaf promoveu a inclusão dos agricultores mais pobres e com menor capacidade de produção na política agrícola brasileira, ainda que de forma desigual, e atualmente, é o principal financiador desse segmento (Gazolla \& Schneider, 2013; Schneider, Mattei \& Cazella, 2004). No entanto, ainda que sejam importantes e necessários, os financiamentos, isoladamente, não são suficientes para a promoção sustentável do desenvolvimento rural.

A política agrícola no Brasil, na realidade, centra-se praticamente no financiamento da produção, sobretudo por meio de estímulos ao crédito rural, ao seguro agrícola e à inserção dos pequenos agricultores no mercado via Pronaf, desconsiderando outras temáticas importantes como a defesa sanitária e iniciativas que viabilizem o aumento da competitividade. No que se refere ao Pronaf, especificamente, o que ocorre é que apesar de ser importante fonte de ações para a pequena produção, restringe-se a um crédito subsidiado que não tem proporcionado mudanças estruturais necessárias à superação dos gargalos que prejudicam a inserção desses agricultores no mercado (Buainain, et al., 2014). Algo preocupante, visto que a agricultura familiar, considerando-se os requisitos delineados pelo Pronaf e a legislação posterior, é predominante em todas as regiões do Brasil, abrangendo 3,9 milhões de estabelecimentos rurais (76,8\% do total) e ocupando 10,1 milhões de trabalhadores (67,0\%) (IBGE, 2017).

Nessa perspectiva, o Nordeste é a região que concentra o maior número de estabelecimentos familiares no país, 1,8 milhões (47,2\%), ocupando a maior área, 25,9 milhões de hectares (32,1\%), e o maior número de trabalhadores que se dedicam às atividades rurais, 4,7 milhões (46,5\%). Ainda assim, é a região que recebe menor volume de recursos do Programa, embora adense os maiores índices de pobreza rural e as maiores limitações para o desenvolvimento da agricultura. Pernambuco, em relação à agricultura familiar nordestina, é o terceiro estado em número de estabelecimentos, abarcando cerca de 232,6 mil (12,6\% do Nordeste), e de mão de obra, ocupando 578,8 mil trabalhadores (12,3\%). E é o quinto no que se refere à área, abrangendo 2,3 milhões de hectares ( $9 \%$ do total), o que demonstra que os estabelecimentos são, em média, menores. Em relação ao Pronaf, mesmo que ainda restrito e pouco abrangente no estado, notam-se evoluções, visto que o acesso aos recursos durante 
muito tempo era praticamente inexiste (Sampaio \& Vital, 2020).

De qualquer forma, ainda são muitas as indagações sobre as assimetrias no acesso ao Pronaf e os efeitos socioeconômicos nos grupos familiares nas diferentes regiões do país. Tal cenário tem indicado falta de capacidade do Programa em atender às diversidades da agricultura familiar (Bianchini, 2015; Souza \& Barbé, 2014). Além disso, demonstra desequilíbrios na distribuição regional de recursos (Araújo \& Vieira Filho, 2018; Bianchini, 2015; Da Silva, et al., 2017; Guanziroli, 2007; Mattei, 2005; Souza \& Barbé, 2014; Pretto \& Horn, 2020).

Deste modo, tendo em vista a heterogeneidade da agricultura familiar e as assimetrias na operacionalização do Pronaf, o presente artigo analisa a evolução dos recursos do Programa nas diferentes atividades (agrícola e pecuária), a partir da divisão de Pernambuco em Regiões de Desenvolvimento (RD), no período de 2013 a 2018. Objetivou-se, nesse sentido, analisar se houve ampliação dos recursos disponibilizados nas diferentes Regiões do estado e como foram operacionalizados no decorrer do período analisado. Para tanto, foi necessário, inicialmente, caracterizar a agricultura familiar nessas RDs, de modo a compreender suas particularidades, considerando-se o número de estabelecimentos, área, mão de obra ocupada e acesso à orientação técnica.

\section{Metodologia}

O presente artigo tem natureza quantitativa que permite a coleta de informações mensuráveis e tratadas, utilizando-se de recursos e técnicas estatísticas (Matias-Pereira, 2010). De forma associada, emprega-se o método analítico-descritivo como instrumento de classificação e interpretação das informações (Pires, 2013). Neste contexto, recorre-se a dados secundários, no período de 2013 a 2018, para analisar a estruturação e evolução do Pronaf nas Regiões de Desenvolvimento (RD) de Pernambuco. Essas informações foram obtidas em duas bases de dados principais: a Matriz de Dados do Crédito Rural (MDCR) do Banco Central do Brasil a respeito do número e valores dos contratos do Pronaf, e o Censo Agropecuário de 2017, por meio do Sistema IBGE de Recuperação Automática (SIDRA), no que tange à caracterização da agricultura familiar.

Após a qualificação dos estabelecimentos familiares pelos dados do Censo Agropecuário foi possível identificar e caracterizar o público enquadrado no Pronaf e contrapô-lo aos dados de acesso efetivo ao Programa. As informações foram consideradas em âmbito municipal e posteriormente aglomeradas por Região de Desenvolvimento, conforme divisão atual do território por Lei Estadual (Lei complementar n ${ }^{\circ} 388$ ).

Recorreu-se também à Taxa Geométrica de Crescimento (TGC) ${ }^{1}$ para analisar os percentuais de incremento ou perda média anual das seguintes variáveis associadas ao Pronaf: a) número de contratos, b) valor dos contratos e c) valor médio dos contratos. Assim, para estimar a TGC utilizou-se o Modelo de Regressão Linear Simples, que possibilitou a verificação do nível de relacionamento entre a variável dependente a apenas uma variável independente ou explicativa (Gujarati, 2006). Nessa perspectiva, a Taxa Geométrica de Crescimento foi dada por meio da expressão:

$$
\boldsymbol{T G C}=(\operatorname{antilog} \beta-1) \times 100
$$

Em que $\beta=$ coeficiente de regressão

Os valores dessa expressão foram estimados a partir do ajuste da seguinte equação, obtida por meio da variável dependente:

$$
\log \left(Y_{t}\right)=\alpha+\beta_{t}+\varepsilon_{t}
$$

\footnotetext{
${ }^{1}$ A TGC é bastante utilizada em análises a respeito da produtividade, mas tem sido empregada também para analisar a evolução do Pronaf, de modo a evidenciar se de fato há crescimento significativo ou não dos recursos disponibilizados pelo Programa. Nesta perspectiva, Monteiro e Lemos (2019) analisaram a distribuição de recursos do Pronaf entre as regiões e estados brasileiros no período de 1999 a 2014. Já Queiroz, Lunas e Frias (2015) analisaram a evolução do Programa no estado de Goiás.
} 
Sendo:

$\mathrm{Y}_{\mathrm{t}}=\mathrm{a}$ variável dependente associada a t-ésima observação

$\alpha=$ constante da regressão

$\beta=$ coeficiente de regressão, que matematicamente é a derivada de $Y_{t}$ em relação a t.

$\varepsilon_{t}=$ termo de erro aleatório

$\mathrm{t}=$ tempo, variável independente ou explicativa de $\mathrm{Y}_{\mathrm{t}}$ em todas as observações.

Quanto ao período de análise escolhido, leva-se em consideração a tendência de redução, de maneira geral, nas regiões do Brasil, do número dos contratos e do montante de recursos entre 2013 e 2018. Até então, apesar de algumas oscilações resultantes muitas vezes de modificações na legislação e na operacionalização, o Pronaf apresentava tendência de crescimento desde sua implementação em 1996 (Pretto \& Horn, 2020).

\section{Resultados e Discussão}

Pernambuco é constituído por 184 municípios e 1 distrito, Fernando de Noronha. Geograficamente, apresenta áreas que remetem a três sub-regiões características do Nordeste (Sertão, Agreste e Zona da Mata), que são definidas segundo aspectos físicos, de clima, vegetação e relevo. Tendo como referência essas sub-regiões, bem como a divisão em Mesorregiões e Microrregiões do $\mathrm{IBGE}^{2}$, o estado foi dividido, administrativamente, em 12 Regiões de Desenvolvimento (RD) (Figura 1).

Figura 1 - Regiões de Desenvolvimento (RD) de Pernambuco, 2020.

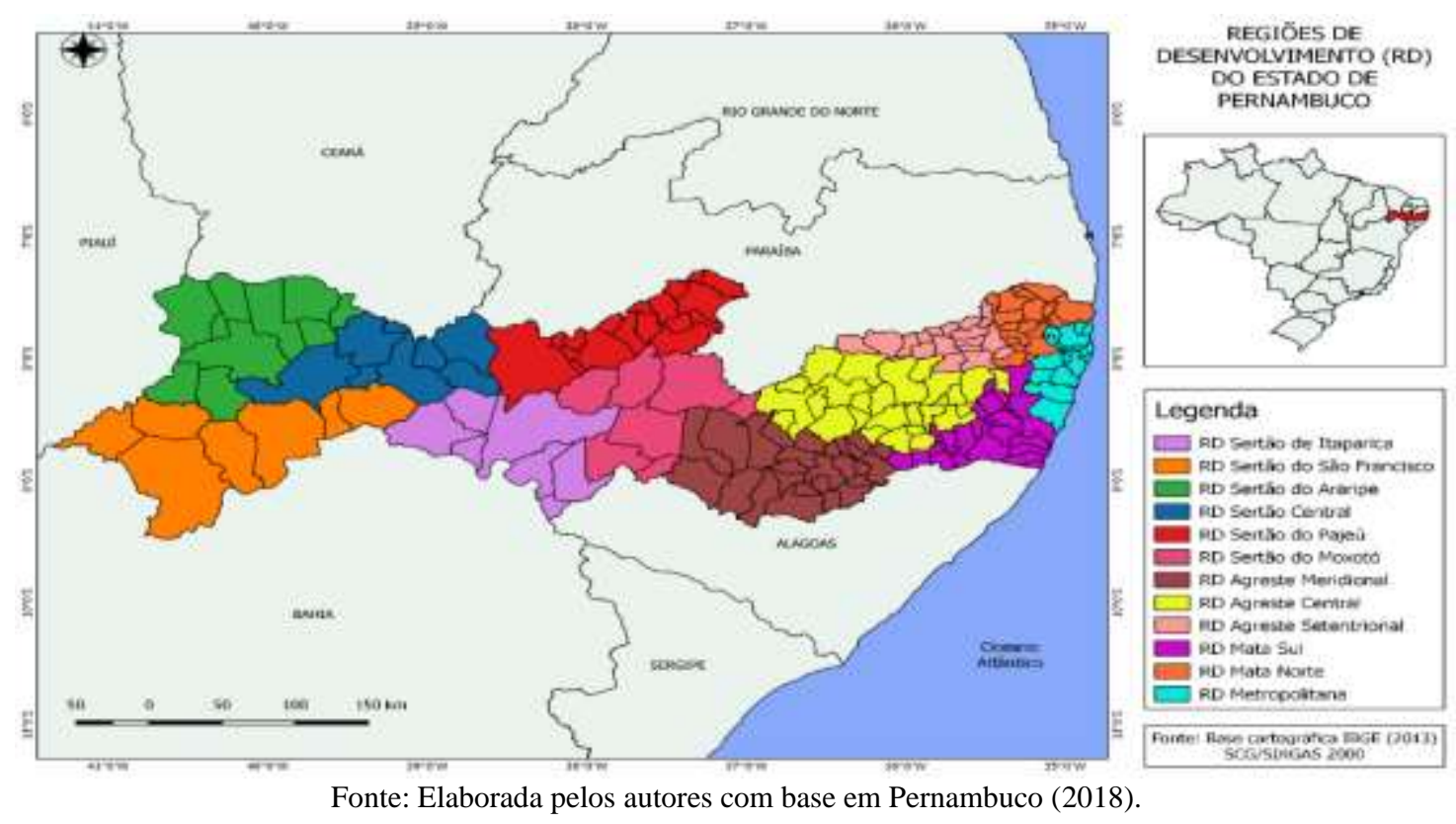

As Regiões de Desenvolvimento do Sertão de Itaparica, Sertão do São Francisco, Sertão do Araripe, Sertão Central, Sertão do Pajeú e Sertão Moxotó estão localizadas nas áreas mais secas. Os estabelecimentos familiares dessas Regiões desenvolvem preferencialmente a pecuária de ovinos e caprinos, criações mais resistentes à seca, além da pecuária bovina de leite e corte. Também se dedicam às culturas temporárias em condições de sequeiro, como feijão e milho, e permanentes, como

\footnotetext{
${ }^{2} \mathrm{O}$ agrupamento de estados e municípios promovido pelo Instituto Brasileiro de Geografia e Estatística (IBGE), com base em Mesorregiões e Microrregiões Geográficas foi definido na década de 90, mas desde 2017, está em processo a implementação de um novo quadro regional que passa a dividir o Brasil em Regiões Geográficas Imediatas e Regiões Geográficas Intermediárias. De qualquer modo, ainda em Lei Estadual vigente em Pernambuco, as Regiões de Desenvolvimento se orientam especificamente pelas Microrregiões.
} 
a banana (IBGE, 2017). Não obstante, sobressaem-se no Sertão do São Francisco setores mais modernos e mecanizados, como o cultivo de frutas irrigadas e produção de sucos e vinhos.

O Agreste Meridional, Agreste Central e Agreste Setentrional estão situados em uma área intermediária, entre a parte mais seca do estado e a úmida. Na agricultura familiar dessas RDs predominam as lavouras temporárias de milho e feijão e a banana, como permanente, bem como a criação de gado de corte e de leite (IBGE, 2017). Essencialmente os municípios do Agreste Meridional constituem a maior bacia leiteira pernambucana.

Já a Mata Norte, Mata Sul e Metropolitana encontram-se na parte mais úmida e fértil, em que se destaca a monocultura de cana-de-açúcar, o cultivo economicamente mais importante de Pernambuco (IBGE, 2017). Apesar dessa produção ser predominantemente em larga escala, a agricultura familiar também se dedica à cultura da cana, visto que as diversas usinas e destilarias constituem canais de comercialização contínuos que viabilizam sua produção (Vital \& Mello, 2010). No entanto, predominam, na maioria dos estabelecimentos, os cultivos de mandioca e feijão e, como cultura permanente, a banana.

Pernambuco tinha, segundo dados do censo agropecuário 2017, 232,6 mil estabelecimentos rurais (82,6\% do total) produzindo nos moldes familiares, ou seja, consoantes com o delineamento estabelecido pelo Pronaf e posteriormente delimitado pela Lei da Agricultura Familiar. Esses estabelecimentos (Tabela 1) concentram-se principalmente nas RDs do Agreste Meridional e Agreste Central e, de forma menos expressiva, na Metropolitana, algo esperado já que é a parte mais urbanizada, e no Sertão de Itaparica.

Tabela 1 - Características dos estabelecimentos familiares nas RD de Pernambuco.

\begin{tabular}{|c|c|c|c|c|c|}
\hline \multirow[t]{2}{*}{ Região de Desenvolvimento } & \multirow[t]{2}{*}{ Número estab. } & \multirow[t]{2}{*}{ Área (ha) } & \multirow{2}{*}{$\begin{array}{c}\text { Número } \\
\text { pessoas ocupadas }\end{array}$} & \multicolumn{2}{|c|}{$\begin{array}{c}\text { Orientação técnica } \\
\text { (Núm. estabelecimentos) }\end{array}$} \\
\hline & & & & Sim & Não \\
\hline Sertão de Itaparica & 8.426 & 140.410 & 24.375 & 628 & 7.798 \\
\hline Sertão do São Francisco & 16.120 & 326.120 & 46.258 & 2.333 & 13.787 \\
\hline Sertão do Araripe & 23.310 & 389.331 & 66.696 & 1.035 & 22.275 \\
\hline Sertão Central & 9.859 & 211.294 & 25.291 & 861 & 8.998 \\
\hline Sertão do Pajeú & 24.403 & 286.986 & 54.120 & 1.601 & 22.802 \\
\hline Sertão do Moxotó & 14.182 & 202.488 & 36.358 & 408 & 13.774 \\
\hline Agreste Meridional & 47.757 & 352.902 & 126.178 & 1.821 & 45.936 \\
\hline Agreste Central & 34.387 & 205.851 & 76.928 & 1.496 & 32.891 \\
\hline Agreste Setentrional & 23.002 & 78.641 & 51.502 & 1.128 & 21.874 \\
\hline Mata Sul & 14.534 & 76.254 & 34.245 & 1.712 & 12.822 \\
\hline Mata Norte & 10.603 & 31.288 & 22.906 & 636 & 9.967 \\
\hline Metropolitana & 6.028 & 19.989 & 14.003 & 357 & 5.671 \\
\hline Pernambuco & 232.611 & 2.321 .554 & 578.860 & 14.016 & 218.595 \\
\hline
\end{tabular}

Fonte: Elaborada pelos autores com base em IBGE (2017).

Embora representem mais de $80 \%$ dos estabelecimentos pernambucanos, a agricultura familiar ocupa pouco mais de $50 \%$ da área (IBGE, 2017). Esses estabelecimentos rurais possuem área média de 10 hectares (ha), inferior à média nordestina, que é de 14,1 ha, e superior apenas aos estados de Alagoas (6,7 ha) e Sergipe (9,4 ha). Em relação às RDs, as médias variam entre 3,0 e 21,4 ha, sendo as áreas dos estabelecimentos localizados no Sertão, em média, maiores do que as do Agreste que, por sua vez, são maiores do que as da Zona da Mata, evidenciando uma associação direta entre as condições edafoclimáticas e a estrutura fundiária nessas Regiões.

Em 2017, as atividades da agricultura familiar em Pernambuco absorveram cerca de 578,9 mil trabalhadores (IBGE, 2017), representando cerca de 74,2\% do total de pessoas ocupadas em estabelecimentos agropecuários. Nesse sentido, esse setor empregou naquele ano uma média de 2,5 pessoas, por unidade de produção, o que não difere muito da média dos outros estados nordestinos, mas superior ao Brasil, o que está em acordo com o seu menor nível tecnológico e de produtividade (Sampaio \& 
Vital, 2020). No contexto nordestino, o Ceará apresentou o menor valor, 2,3 pessoas/estabelecimento, e o Rio Grande do Norte e Maranhão os maiores, com 2,9 pessoas/estabelecimento.

Entre as RDs de Pernambuco essa média também não varia de forma significativa. O Sertão de Itaparica, Sertão do São Francisco e Sertão do Araripe são as Regiões que apresentam a maior média de pessoas ocupadas por estabelecimento rural, 2,9. Já o Agreste Central, Agreste Setentrional, Sertão do Pajeú e Mata Norte são as que apresentaram a menor ocupação, com 2,2 pessoas/estabelecimento. Deve-se ressaltar, nesse sentido, que a absorção e valorização da mão de obra familiar nos estabelecimentos rurais contribuem para a diminuição das desigualdades entre as rendas rurais e urbanas, bem como possibilitam a permanência e sobrevivência dos agricultores nas áreas rurais. Logo, políticas públicas que atuem efetivamente nessa direção, fortalecendo as atividades produtivas familiares, são essenciais no processo de desenvolvimento rural.

Ainda de acordo com o Censo Agropecuário de 2017, apenas 14 mil (6,0\%) estabelecimentos familiares pernambucanos receberam orientação técnica naquele ano. Na região Nordeste, o percentual é de 7,3\%, perfazendo cerca de 134,8 mil estabelecimentos, sendo 71,6 mil deles (53,1\%) situados na Bahia e no Ceará. No entanto, é a Paraíba e o Rio Grande do Norte que apresentaram os melhores percentuais, $16,8 \%$ e 14,0\%, já que em termos relativos, os percentuais da Bahia e Ceará foram de $6,7 \%$ e $10,8 \%$, respectivamente.

Pela perspectiva das RDs (Tabela 1), 6 das 12 Regiões estão acima da média de orientação técnica do estado, o que ainda assim é baixa. De qualquer forma, as RDs Sertão do São Francisco (14,5\%) e a Mata Sul (11,8\%) são as que possuem os maiores percentuais. A RD Sertão do São Francisco tradicionalmente atrai um conjunto significativo de políticas públicas, inclusive de assistência técnica, que utilizam seu potencial hídrico para a aprimoramento das ações. Neste contexto, a agricultura familiar que utiliza irrigação encontra-se prioritariamente associada a projetos públicos estaduais e a perímetros irrigados, como os implantados pelo Departamento Nacional de Obras Contra a Seca (DNOCS) e a Companhia de Desenvolvimento do Vale do São Francisco (CODEVASF).

No caso da Mata Sul, esse percentual parece refletir esforço das entidades públicas em gerar renda e diversificação da produção para os pequenos agricultores, de modo a modificar o quadro de degradação ambiental e de desequilíbrios socioeconômicos que atualmente configuram a Região. Vale esclarecer que a partir da década de 1990, com a crise da indústria sucroalcooleira e falência de usinas do segmento, houve aumento do desemprego e da pobreza rural, ao mesmo tempo em que se observou ampliação da demanda por terra, desencadeando processos de ocupação e desapropriação de engenhos falidos, trazendo nova configuração social e fundiária à Mata Sul, antes constituída quase que exclusivamente por latifúndios (Sigaud \& L'estoile, 2006).

No período de 2013 a 2018, os estabelecimentos familiares pernambucanos formalizaram 600,2 mil contratos do Pronaf, totalizando cerca de $\mathrm{R}$ \$2,9 bilhões. Esse panorama representa 11,8\% do número de contratos e 12,9\% dos valores monetários financiados no Nordeste, o que se mostra compatível com o percentual de estabelecimentos que o estado reflete no contexto da agricultura familiar nordestina (12,6\%). Constatou-se também que 75,4\% do número de contratos e 72,9\% do montante de recursos foram destinados às atividades pecuárias e, respectivamente, $24,6 \%$ e 27,1\% a atividades agrícolas. A exceção foi o ano de 2013, que apresentou o maior número e valor de contratos com predomínio do financiamento agrícola. 
Tabela 2 - Número de contratos do Pronaf nas RDs de Pernambuco, por atividade de 2013 a 2018 (em 1.000).

\begin{tabular}{|c|c|c|c|c|c|c|c|c|c|}
\hline RD & Atividade & 2013 & 2014 & 2015 & 2016 & 2017 & 2018 & $\begin{array}{c}2013 \text { a } \\
2018\end{array}$ & $\begin{array}{c}\text { TGC } \\
(\% \text { a.a. })\end{array}$ \\
\hline \multirow{3}{*}{$\begin{array}{l}\text { Sertão de } \\
\text { Itaparica }\end{array}$} & Agrícola & 2,97 & 1,09 & 0,77 & 0,96 & 1,33 & 1,38 & 8,51 & $-8,61^{\mathrm{ns}}$ \\
\hline & Pecuária & 3,83 & 3,71 & 4,37 & 5,17 & 4,85 & 4,35 & 26,27 & $4,59 * *$ \\
\hline & Total & 6,80 & 4,80 & 5,14 & 6,13 & 6,18 & 5,73 & 34,78 & $0,22^{\mathrm{ns}}$ \\
\hline \multirow{3}{*}{$\begin{array}{l}\text { Sertão do São } \\
\text { Francisco }\end{array}$} & Agrícola & 5,69 & 1,51 & 0,74 & 0,78 & 1,01 & 1,11 & 10,84 & $-26,6 * *$ \\
\hline & Pecuária & 7,39 & 6,07 & 6,58 & 6,59 & 7,61 & 6,75 & 40,99 & $0,64^{\mathrm{ns}}$ \\
\hline & Total & 13,08 & 7,58 & 7,32 & 7,37 & 8,63 & 7,86 & 51,83 & $-6,15^{\mathrm{ns}}$ \\
\hline \multirow{3}{*}{$\begin{array}{l}\text { Sertão do } \\
\text { Araripe }\end{array}$} & Agrícola & 8,43 & 4,23 & 1,15 & 1,22 & 1,31 & 1,55 & 17,89 & $-34,07 *$ \\
\hline & Pecuária & 8,62 & 10,50 & 16,31 & 14,56 & 14,46 & 11,53 & 75,97 & $6,57^{\mathrm{ns}}$ \\
\hline & Total & 17,05 & 14,73 & 17,47 & 15,78 & 15,77 & 13,07 & 93,86 & $-3.50^{\mathrm{ns}}$ \\
\hline \multirow{3}{*}{ Sertão Central } & Agrícola & 2,60 & 1,01 & 0,13 & 0,23 & 0,31 & 0,23 & 4,52 & $-43,13 * *$ \\
\hline & Pecuária & 2,60 & 4,23 & 4,58 & 4,14 & 4,64 & 4,50 & 24,69 & $8,34 * *$ \\
\hline & Total & 5,20 & 5,25 & 4,71 & 4,36 & 4,95 & 4,74 & 29,21 & $-2,05^{\mathrm{ns}}$ \\
\hline \multirow{3}{*}{ Sertão do Pajeú } & Agrícola & 7,02 & 1,63 & 0,49 & 0,46 & 0,66 & 1,82 & 12,08 & $-27,21^{\mathrm{ns}}$ \\
\hline & Pecuária & 2,82 & 5,93 & 7,43 & 6,99 & 6,94 & 6,05 & 36,16 & $12,07^{\mathrm{ns}}$ \\
\hline & Total & 9,84 & 7,55 & 7,92 & 7,45 & 7,60 & 7,87 & 48,23 & $-3,31^{\text {ns }}$ \\
\hline \multirow{3}{*}{ Sertão do Moxotó } & Agrícola & 3,27 & 0,44 & 0,43 & 0,26 & 0,18 & 0,36 & 4,95 & $-40,61 * *$ \\
\hline & Pecuária & 2,36 & 3,05 & 2,61 & 2,33 & 2,64 & 2,90 & 15,89 & $1,38^{\mathrm{ns}}$ \\
\hline & Total & 5,63 & $\mathbf{3 , 5 0}$ & 3,04 & 2,59 & 2,83 & 3,26 & 20,84 & $-10,1^{\mathrm{ns}}$ \\
\hline \multirow{3}{*}{$\begin{array}{c}\text { Agreste } \\
\text { Meridional }\end{array}$} & Agrícola & 9,21 & 3,27 & 0,41 & 0,59 & 0,89 & 2,31 & 16,67 & $-29,87^{\mathrm{ns}}$ \\
\hline & Pecuária & 7,17 & 15,98 & 17,73 & 18,65 & 20,10 & 17,66 & 97,30 & $14,98^{* *}$ \\
\hline & Total & 16,38 & 19,25 & 18,14 & 19,24 & 20,99 & 19,98 & 113,96 & $3,75^{*}$ \\
\hline \multirow{3}{*}{ Agreste Central } & Agrícola & 8,47 & 3,93 & 2,34 & 2,47 & 2,71 & 3,08 & 22,99 & $-17,48^{* *}$ \\
\hline & Pecuária & 5,59 & 8,35 & 11,25 & 12,25 & 11,74 & 11,64 & 60,82 & $13,64 *$ \\
\hline & Total & 14,05 & 12,28 & 13,59 & 14,71 & 14,45 & 14,72 & 83,80 & $2,28^{n s}$ \\
\hline \multirow{3}{*}{$\begin{array}{c}\text { Agreste } \\
\text { Setentrional }\end{array}$} & Agrícola & 3,36 & 2,31 & 1,24 & 1,24 & 0,96 & 1,06 & 10,17 & $-24,00 *$ \\
\hline & Pecuária & 4,80 & 5,83 & 8,27 & 6,98 & 5,57 & 5,60 & 37,05 & $1,32^{\mathrm{ns}}$ \\
\hline & Total & 8,16 & 8,14 & 9,51 & 8,22 & 6,53 & 6,66 & 47,22 & $-5,20 * *$ \\
\hline \multirow{3}{*}{ Mata Sul } & Agrícola & 5,04 & 4,18 & 2,97 & 3,59 & 4,00 & 4,22 & 23,98 & $-2,37^{\mathrm{ns}}$ \\
\hline & Pecuária & 0,85 & 1,94 & 2,60 & 1,98 & 1,87 & 1,73 & 10,97 & $9,05^{\mathrm{ns}}$ \\
\hline & Total & 5,89 & 6,12 & 5,56 & 5,56 & 5,87 & 5,95 & 34,95 & $-0,22^{\mathrm{ns}}$ \\
\hline \multirow{3}{*}{ Mata Norte } & Agrícola & 4,24 & 1,71 & 0,79 & 0,96 & 1,19 & 1,23 & 10,12 & $-20,22 * *$ \\
\hline & Pecuária & 3,14 & 4,63 & 6,00 & 4,99 & 3,26 & 2,77 & 24,78 & $-5,32^{\mathrm{ns}}$ \\
\hline & Total & 7,38 & 6,34 & 6,78 & 5,95 & 4,44 & 4,01 & 34,90 & $-12,14 *$ \\
\hline \multirow{3}{*}{ Metropolitana } & Agrícola & 0,95 & 0,68 & 0,71 & 1,25 & 0,68 & 0,78 & 5,06 & $-1,20^{\mathrm{ns}}$ \\
\hline & Pecuária & 0,05 & 0,34 & 0,39 & 0,26 & 0,17 & 0,38 & 1,58 & $21,87^{\mathrm{ns}}$ \\
\hline & Total & 1,01 & 1,01 & 1,10 & 1,51 & $\mathbf{0 , 8 5}$ & 1,16 & 6,64 & $-1,45^{\mathrm{ns}}$ \\
\hline \multirow{3}{*}{ Pernambuco } & Agrícola & 61,25 & 25,98 & 12,16 & 13,99 & 15,22 & 19,14 & 147,75 & $-20,79 * *$ \\
\hline & Pecuária & 49,22 & 70,54 & 88,12 & 84,87 & 83,85 & 75,87 & 452,46 & $7,55^{* *}$ \\
\hline & Total & 110,47 & 96,52 & 100,28 & 98,86 & 99,07 & 95,01 & 600,21 & $-1,97 * *$ \\
\hline
\end{tabular}

ns: Estatisticamente não significativa.

* Estatisticamente significativa a 5\% de probabilidade.

** Estatisticamente significativa a $10 \%$ de probabilidade.

Fonte: Elaborada pelos autores com base em BACEN (2020).

Analisando a distribuição do Pronaf, a partir das RDs pernambucanas (Tabela 2), percebeu-se disparidades no número e valores de contratos, mas também semelhanças, como a predominância dos financiamentos da atividade pecuária. De acordo com Vital e Melo (2015), essa conjuntura demonstra que a agricultura familiar tem no setor pecuário uma espécie de poupança familiar com bastante liquidez, ou seja, produtos que podem ser vendidos rapidamente em caso de necessidade. Somente as RDs Metropolitana e Mata Sul apresentaram maior destinação dos contratos para atividades agrícolas. Tendo em vista que essas duas Regiões se localizam nas terras mais férteis, justifica-se em parte um investimento mais expressivo na agricultura. No entanto, ao considerar que cerca de $50 \%$ dos estabelecimentos familiares do estado se dedicam às culturas temporárias, permanentes e 
horticultura (IBGE, 2017), explicitam-se as desigualdades entre as RDs e o menor aporte financeiro recebido pelos agricultores no desenvolvimento de atividades agrícolas.

Inferiu-se também que as RDs Agreste Meridional, Sertão do Araripe e Agreste Central reuniram o maior número de contratos totais, representando juntas 48,6\%, sendo igualmente as mais expressivas quanto aos contratos da pecuária $(51,7 \%)$. Em relação às atividades agrícolas, as Regiões da Mata Sul, Agreste Central e Sertão do Araripe foram as mais representativas (43,9\%). Por outro lado, as RDs Metropolitana e Sertão do Moxotó apresentaram o menor número de contratos totais (4,6\%), explicitando mais uma vez esse panorama de diferenças de acesso entre as Regiões.

Sem diferenciar o tipo de atividade produtiva financiada, constatou-se que 9 RDs tiveram queda no número total de contratos do Pronaf. No entanto, em termos de TGC, isto é, em relação à taxa de diminuição ou crescimento ocorrido ao ano, constatou-se que somente foram significativas, estatisticamente, as quedas na RD Mata Norte (-12,14\%) e Agreste Setentrional $(-5,20 \%)$. Quanto às Regiões em que o número de contratos aumentou, apenas na RD Agreste Meridional (3,75\%) foi estatisticamente significativo. Isso demonstrou uma pequena ampliação das operações do Pronaf e apenas na RD com maior participação no Programa. Analisando o contexto geral de Pernambuco mostrou leve queda anual significativa (-1,97\%), o que evidenciou diminuição dos contratos acessados no estado ao ano, no período de 2013 a 2018.

Distinguindo-se por atividade produtiva (Tabela 2), percebeu-se uma queda no número de contratos destinados às atividades agrícolas em todas as RDs. Os dados sinalizam que em 7 delas as quedas ao ano tiveram significância e foram bastante expressivas, sendo as piores taxas percebidas na RD Sertão Central (3,13\%) e Sertão do Moxotó $(0,61 \%)$. Interessante perceber que todas essas Regiões com quedas significativas são áreas com perfil de contratos tipicamente voltados à pecuária, mas que apresentaram uma expansão atípica dos contratos agrícolas, tendo em vista o restante do período, sobretudo no ano de 2013. Em relação à pecuária houve aumento, com exceção da RD Mata Norte, mas apenas em 4 regiões, esse crescimento foi significativo: Agreste Meridional (14,98\%), Agreste Central (13,64\%), Sertão Central (8,34\%) e Sertão de Itaparica (4,59\%).

No que tange a Pernambuco, revelou-se queda significativa e expressiva no número de contratos agrícolas $(-20,79 \%)$ e aumento também significativo nos contratos da pecuária $(7,55 \%)$. Essa conjuntura demonstrou que os contratos agrícolas se ampliaram abruptamente bem no início do período, mas esse aumento não se sustentou no decorrer dos anos analisados. Já com os contratos da pecuária teve-se uma diminuição expressiva inicial, mas que logo se ampliou e se manteve, sendo capaz de resultar em um certo crescimento.

Quanto aos valores totais (Tabela 3), de forma similar ao que ocorreu no número de contratos, têm-se as RDs Agreste Meridional, Sertão do Araripe e Agreste Central concentrando a maior porcentagem total (51,2\%), bem como sendo as principais contratantes de financiamentos da pecuária (57,4\%). Igualmente, as RDs Mata Sul, Agreste Central e Sertão do Araripe apareceram como as mais representativas em contratos da atividade agrícola $(47,1 \%)$. Além disso, novamente o menor montante de recursos (5,8\% do total) deu-se na Região Metropolitana e Sertão do Moxotó. Ademais, 10 RDs apresentaram diminuição nos valores monetários totais dos contratos, porém, a queda ao ano, ou seja, a diminuição dos recursos acessados, foi significativa apenas em Sertão do Moxotó (-13,6\%), Sertão do Araripe (-7,8\%), Sertão do Pajeú (-6,72\%) e Mata Norte (-4,29\%). As RDs que aumentaram os valores dos contratos, não se mostraram significativos. No que diz respeito a Pernambuco, houve uma leve queda ao ano, porém não significativa, o que indicou estabilidade nos valores do Pronaf financiados no estado.

Examinando-se agora por atividade produtiva, percebeu-se que os valores dos contratos agrícolas do Pronaf diminuíram em todas as RDs, sendo que em 7 delas foram significativas e muito expressivas. Entre as maiores quedas estão Agreste Central (-52,06\%) e Sertão do Moxotó (-47,47\%). Em panorama oposto, os contratos da atividade pecuária aumentaram na totalidade das Regiões, mas só foram significativos na RD Agreste Central (10,93\%), Agreste Setentrional (10,65\%) e Sertão de Itaparica $(4,40 \%)$. Em relação ao desempenho estadual, revelou-se uma considerável e significativa queda dos valores dos contratos 
agrícolas $(-20,64)$ e um leve aumento ao ano, mas não significativo, dos contratos da pecuária. Esse comportamento indica que, provavelmente, o comportamento atípico tenha sido o aumento inicial e não a diminuição posterior.

Tabela 3 - Valor dos contratos do Pronaf nas RDs de Pernambuco, por atividade de 2013 a 2018 (em R\$1.000.000,00).

\begin{tabular}{|c|c|c|c|c|c|c|c|c|c|}
\hline RD & Atividade & 2013 & 2014 & 2015 & 2016 & 2017 & 2018 & $\begin{array}{c}2013 \text { a } \\
2018\end{array}$ & $\begin{array}{c}\text { TGC } \\
(\% \text { a.a }) \\
\end{array}$ \\
\hline \multirow{3}{*}{$\begin{array}{l}\text { Sertão de } \\
\text { Itaparica }\end{array}$} & Agrícola & 13,42 & 8,07 & 4,28 & 4,18 & 5,59 & 5,95 & 41,50 & $-14,83^{* *}$ \\
\hline & Pecuária & 15,34 & 17,71 & 18,31 & 20,03 & 20,48 & 18,80 & 110,67 & $4,40 *$ \\
\hline & Total & 28,77 & 25,78 & 22,59 & 24,21 & 26,07 & 24,75 & 152,17 & $-1,85^{\mathrm{ns}}$ \\
\hline \multirow{3}{*}{$\begin{array}{l}\text { Sertão do São } \\
\text { Francisco }\end{array}$} & Agrícola & 25,42 & 15,27 & 6,99 & 4,65 & 6,92 & 8,35 & 67,60 & $-23,85^{* *}$ \\
\hline & Pecuária & 36,91 & 32,46 & 29,45 & 28,39 & 35,50 & 37,24 & 199,95 & $0,78^{\text {ns }}$ \\
\hline & Total & 62,33 & 47,73 & 36,44 & 33,04 & 42,42 & 45,58 & 267,55 & $-5,76^{\mathrm{ns}}$ \\
\hline \multirow{3}{*}{$\begin{array}{l}\text { Sertão do } \\
\text { Araripe }\end{array}$} & Agrícola & 32,17 & 17,95 & 4,44 & 3,70 & 5,30 & 5,90 & 69,45 & $-35,2 * *$ \\
\hline & Pecuária & 44,02 & 70,00 & 73,45 & 57,05 & 56,80 & 52,96 & 354,27 & $6,57^{\mathrm{ns}}$ \\
\hline & Total & 76,18 & 87,95 & 77,89 & 60,75 & 62,09 & 58,86 & 423,72 & $-7,38 *$ \\
\hline \multirow{3}{*}{ Sertão Central } & Agrícola & 9,94 & 6,95 & 1,31 & 1,33 & 1,13 & 0,77 & 21,43 & $-52,06 *$ \\
\hline & Pecuária & 13,47 & 33,66 & 22,79 & 17,67 & 22,74 & 22,06 & 132,41 & $2,95^{\mathrm{ns}}$ \\
\hline & Total & 23,42 & 40,61 & 24,11 & 19,00 & 23,86 & 22,84 & 153,84 & $-5,60^{\text {ns }}$ \\
\hline \multirow{3}{*}{ Sertão do Pajeú } & Agrícola & 28,39 & 6,94 & 1,93 & 1,81 & 2,17 & 5,15 & 46,39 & $-34,56^{\mathrm{ns}}$ \\
\hline & Pecuária & 8,98 & 27,10 & 26,75 & 22,63 & 25,26 & 22,29 & 133,02 & $11,9^{\text {ns }}$ \\
\hline & Total & 37,37 & 34,04 & 28,69 & 24,44 & 27,43 & 27,45 & 179,42 & $-6,72 *$ \\
\hline \multirow{3}{*}{$\begin{array}{l}\text { Sertão do } \\
\text { Moxotó }\end{array}$} & Agrícola & 15,79 & 4,58 & 4,69 & 2,02 & 0,96 & 1,72 & 29,76 & $-47,47 *$ \\
\hline & Pecuária & 9,79 & 18,60 & 10,24 & 8,42 & 12,37 & 13,06 & 72,49 & $0,06^{\mathrm{ns}}$ \\
\hline & Total & 25,58 & 23,19 & 14,92 & 10,44 & 13,34 & 14,78 & 102,24 & $-13,60 * *$ \\
\hline \multirow{3}{*}{$\begin{array}{c}\text { Agreste } \\
\text { Meridional }\end{array}$} & Agrícola & 34,46 & 18,04 & 2,26 & 2,41 & 2,36 & 6,76 & 66,28 & $-40,51^{\mathrm{ns}}$ \\
\hline & Pecuária & 73,27 & 139,30 & 87,89 & 82,35 & 92,61 & 105,73 & 581,15 & $1,55^{\mathrm{ns}}$ \\
\hline & Total & 107,73 & 157,34 & 90,15 & 84,76 & 94,98 & 112,48 & 647,43 & $-3,88^{\text {ns }}$ \\
\hline \multirow{3}{*}{ Agreste Central } & Agrícola & 36,82 & 30,56 & 20,60 & 20,34 & 18,79 & 18,71 & 145,84 & $-13,87 *$ \\
\hline & Pecuária & 29,11 & 46,88 & 45,74 & 42,46 & 53,92 & 58,42 & 276,54 & $10,93 * *$ \\
\hline & Total & 65,93 & 77,45 & 66,35 & 62,80 & 72,71 & 77,14 & 422,37 & $1,54^{\text {ns }}$ \\
\hline \multirow{3}{*}{$\begin{array}{c}\text { Agreste } \\
\text { Setentrional }\end{array}$} & Agrícola & 9,66 & 9,99 & 5,76 & 4,79 & 4,80 & 4,51 & 39,51 & $-17,69^{*}$ \\
\hline & Pecuária & 12,91 & 18,97 & 21,49 & 18,70 & 22,65 & 25,16 & 119,89 & $10,65^{*}$ \\
\hline & Total & 22,58 & 28,96 & 27,25 & 23,49 & 27,45 & 29,67 & 159,39 & $3,02^{\mathrm{ns}}$ \\
\hline \multirow{3}{*}{ Mata Sul } & Agrícola & 30,31 & 35,98 & 21,38 & 15,83 & 23,51 & 28,22 & 155,23 & $-5,52^{\mathrm{ns}}$ \\
\hline & Pecuária & 4,19 & 9,32 & 10,94 & 6,65 & 7,82 & 8,84 & 47,76 & $7,73^{\mathrm{ns}}$ \\
\hline & Total & 34,50 & 45,30 & 32,33 & 22,48 & 31,33 & 37,06 & 203,00 & $-3,17^{\text {ns }}$ \\
\hline \multirow{3}{*}{ Mata Norte } & Agrícola & 14,26 & 7,84 & 4,38 & 4,30 & 5,86 & 5,86 & 42,50 & $-15,25^{\mathrm{ns}}$ \\
\hline & Pecuária & 8,79 & 13,76 & 16,77 & 13,29 & 13,07 & 13,31 & 78,99 & $4,82^{\mathrm{ns}}$ \\
\hline & Total & 23,06 & 21,60 & 21,15 & 17,58 & 18,94 & 19,16 & 121,49 & $-4,29 *$ \\
\hline \multirow{3}{*}{ Metropolitana } & Agrícola & 10,28 & 9,82 & 9,37 & 23,53 & 3,30 & 4,61 & 60,91 & $-18,17^{\mathrm{ns}}$ \\
\hline & Pecuária & 0,24 & 0,99 & 1,23 & 0,94 & 0,71 & 1,28 & 5,39 & $20,29^{\mathbf{n s}}$ \\
\hline & Total & 10,52 & 10,81 & 10,60 & 24,47 & 4,02 & 5,88 & 66,30 & $-14,40^{\mathrm{ns}}$ \\
\hline \multirow{3}{*}{ Pernambuco } & Agrícola & 260,93 & 172,00 & 87,39 & 88,87 & 80,70 & 96,50 & 786,39 & $-20,64 *$ \\
\hline & Pecuária & 257,02 & 428,75 & 365,07 & 318,58 & 363,94 & 379,16 & $2.112,52$ & $3,76^{\mathrm{ns}}$ \\
\hline & Total & 517,95 & 600,75 & 452,45 & 407,45 & 444,64 & 475,66 & $2.898,91$ & $-4,1^{\mathrm{ns}}$ \\
\hline
\end{tabular}

ns: Estatisticamente não significativa.

* Estatisticamente significativa a 5\% de probabilidade.

** Estatisticamente significativa a $10 \%$ de probabilidade.

Fonte: Elaborada pelos autores com base em BACEN (2020).

Tendo em vista o comportamento supracitado dos contratos do Pronaf (Tabela 2 e 3), explicitou-se que as oscilações no número e valores monetários do Programa só foram expressivas ao se distinguir os contratos por atividade financiada. Em Pernambuco, bem como nas distintas RDs (com exceção da Mata Sul e Metropolitana), observou-se predominância dos financiamentos de atividades pecuárias no decorrer do período, todavia, em 2013, houve uma equidade incomum entre os contratos agrícolas e da pecuária. 
Essa alteração e variação acentuada no perfil dos contratos, em termos absolutos, principalmente entre 2013 e 2015 , pode estar associada a uma grave seca que se instaurou em todo Nordeste no período de 2012 a 2017 (Buriti \& Barbosa, 2018). Esse contexto levou a uma maior disponibilização do crédito do Programa, principalmente com a finalidade de investimento, tradicionalmente mais representativa em Pernambuco e que correspondeu, entre 2013 e 2018, a cerca de 92,5\% do número e $82,5 \%$ dos recursos financiados na pecuária, além de 95,9\% do número e $83,8 \%$ dos recursos na atividade agrícola. Dessa forma, em 2012, foram instituídas linhas especiais de investimento e custeio destinadas aos beneficiários afetados pela seca ou estiagem na área de atuação da Superintendência do Desenvolvimento do Nordeste (SUDENE), com recursos do Fundo Constitucional de Financiamento do Nordeste (FNE).

Os contratos de investimento agrícola foram os que se expandiram primeiro com esse aporte, sobretudo na modalidade "aquisição de animais de serviço para uso na agricultura", no caso bovinos, apresentando um pico no número e valores, logo em 2013, na maioria das RDs, uma queda considerável até 2015 com certa estabilidade, na sequência, até 2018. Esse contexto do ano de 2013 chamou atenção, pois em meio à seca extrema, animais criados em regime extensivo, predominantes no estado, morreram aos milhares por falta de alimentação e água, e as plantações seguiram o mesmo caminho, com perdas em massa. Já em um segundo momento, essa ampliação dos créditos disponibilizados foi mais contundente no número e valores dos contratos de investimento da atividade pecuária e atrelada à modalidade de aquisição de animais basicamente bovinos, provavelmente um esforço de recuperar o rebanho perdido, atingindo um pico em 2014, com uma constância posterior até 2018.

Como consequência do contexto apresentado, torna-se relevante também analisar a relação entre o número e os valores dos contratos, ou seja, os valores médios entre 2013 e 2018 (Tabela 4). Constatou-se que o maior valor médio total ocorreu na RD Metropolitana, quase o dobro da Mata Sul, a segunda maior, ambas em que predominaram as atividades agrícolas. Já os menores valores ocorreram no Agreste Setentrional, Mata Norte e Sertão do Pajeú. Esta situação demonstrou que os agricultores mais capitalizados, com maior capacidade de pagamento, concentraram-se sobretudo na Região Metropolitana de Pernambuco e se dedicaram às atividades agrícolas de cadeias produtivas mais dinâmicas, visto o valor médio destoante do restante das RDs. Nessa mesma perspectiva, os mais pobres concentraram-se em áreas de sertão e agreste, dedicando-se a pecuária, e na RD Mata Norte, em cadeias produtivas agrícolas menos estruturadas.

Tabela 4 - Valor Médio dos contratos do Pronaf nas RDs de Pernambuco, por atividade de 2013 a 2018 (em R\$1.000,00).

\begin{tabular}{|c|c|c|c|c|c|c|c|c|c|}
\hline RD & Atividade & 2013 & 2014 & 2015 & 2016 & 2017 & 2018 & 2013 a 2018 & TGC (\% a.a) \\
\hline \multirow{3}{*}{ Sertão de Itaparica } & Agrícola & 4,52 & 7,38 & 5,54 & 4,36 & 4,20 & 4,32 & 4,88 & $-6,16^{\mathrm{ns}}$ \\
\hline & Pecuária & 4,01 & 4,78 & 4,19 & 3,88 & 4,23 & 4,32 & 4,21 & $-0,20^{\mathrm{ns}}$ \\
\hline & Total & 4,23 & 5,37 & 4,39 & 3,95 & 4,22 & 4,32 & 4,38 & $-2,06^{\mathrm{ns}}$ \\
\hline \multirow{3}{*}{ Sertão do São Francisco } & Agrícola & 4,47 & 10,10 & 9,46 & 5,96 & 6,84 & 7,52 & 6,23 & $2,77^{\mathrm{ns}}$ \\
\hline & Pecuária & 4,99 & 5,35 & 4,48 & 4,31 & 4,66 & 5,52 & 4,88 & $0,14^{\mathrm{ns}}$ \\
\hline & Total & 4,76 & 6,29 & 4,98 & 4,49 & 4,92 & 5,80 & 5,16 & $\mathbf{0 , 4 2 ^ { \mathrm { ns } }}$ \\
\hline \multirow{3}{*}{ Sertão do Araripe } & Agrícola & 3,82 & 4,24 & 3,85 & 3,04 & 4,05 & 3,81 & 3,88 & $-1,10^{\mathrm{ns}}$ \\
\hline & Pecuária & 5,11 & 6,67 & 4,50 & 3,92 & 3,93 & 4,60 & 4,66 & $-6,43^{\mathrm{ns}}$ \\
\hline & Total & 4,47 & 5,97 & 4,46 & 3,85 & 3,94 & 4,50 & 4,51 & $-3,89^{\mathrm{ns}}$ \\
\hline \multirow{3}{*}{ Sertão Central } & Agrícola & 3,82 & 6,86 & 10,25 & 5,84 & 3,64 & 3,30 & 4,75 & $-9,12^{\mathrm{ns}}$ \\
\hline & Pecuária & 5,18 & 7,95 & 4,98 & 4,27 & 4,90 & 4,90 & 5,36 & $-5,38^{\mathrm{ns}}$ \\
\hline & Total & 4,50 & 7,74 & 5,12 & 4,35 & 4,82 & 4,82 & 5,27 & $-3,54^{\mathrm{ns}}$ \\
\hline \multirow{3}{*}{ Sertão do Pajeú } & Agrícola & 4,04 & 4,27 & 3,99 & 3,93 & 3,29 & 2,82 & 3,84 & $-7,41^{*}$ \\
\hline & Pecuária & 3,18 & 4,57 & 3,60 & 3,24 & 3,64 & 3,69 & 3,68 & $-0,12^{\mathrm{ns}}$ \\
\hline & Total & 3,80 & 4,51 & 3,62 & 3,28 & 3,61 & 3,49 & 3,72 & $-3,40^{\mathrm{ns}}$ \\
\hline \multirow{3}{*}{ Sertão do Moxotó } & Agrícola & 4,83 & 10,37 & 10,82 & 7,79 & 5,26 & 4,75 & 6,02 & $-6,99^{\text {ns }}$ \\
\hline & Pecuária & 4,14 & 6,09 & 3,92 & 3,62 & 4,68 & 4,51 & 4,56 & $-1,26^{\mathrm{ns}}$ \\
\hline & Total & 4,54 & 6,63 & 4,91 & 4,03 & 4,72 & 4,54 & 4,91 & $-3,48^{\mathrm{ns}}$ \\
\hline \multirow{2}{*}{ Agreste Meridional } & Agrícola & 3,74 & 5,52 & 5,56 & 4,11 & 2,67 & 2,92 & 3,98 & $-10,62^{\mathrm{ns}}$ \\
\hline & Pecuária & 10,22 & 8,72 & 4,96 & 4,42 & 4,61 & 5,99 & 5,97 & $1,55^{\mathrm{ns}}$ \\
\hline
\end{tabular}


Research, Society and Development, v. 10, n. 10, e59101018466, 2021

(CC BY 4.0) | ISSN 2525-3409 | DOI: http://dx.doi.org/10.33448/rsd-v10i10.18466

\begin{tabular}{|c|c|c|c|c|c|c|c|c|c|}
\hline & Total & 6,58 & 8,18 & 4,97 & 4,41 & 4,53 & 5,63 & 5,68 & $-7,63^{\mathrm{ns}}$ \\
\hline \multirow{3}{*}{ Agreste Central } & Agrícola & 4,35 & 7,78 & 8,81 & 8,25 & 6,94 & 6,08 & 6,34 & $3,61^{\mathrm{ns}}$ \\
\hline & Pecuária & 5,21 & 5,62 & 4,07 & 3,47 & 4,59 & 5,02 & 4,55 & $-2,72^{\mathrm{ns}}$ \\
\hline & Total & 4,69 & 6,31 & 4,88 & 4,27 & 5,03 & 5,24 & 5,04 & $-0,74^{\mathrm{ns}}$ \\
\hline \multirow{3}{*}{ Agreste Setentrional } & Agrícola & 2,87 & 4,32 & 4,63 & 3,87 & 5,01 & 4,25 & 3,88 & $6,36 * *$ \\
\hline & Pecuária & 2,69 & 3,26 & 2,60 & 2,68 & 4,07 & 4,49 & 3,24 & $10,65^{*}$ \\
\hline & Total & 2,77 & 3,56 & 2,86 & 2,86 & 4,21 & 4,45 & 3,38 & $8,20 * *$ \\
\hline \multirow{3}{*}{ Mata Sul } & Agrícola & 6,02 & 8,62 & 7,21 & 4,42 & 5,88 & 6,69 & 6,47 & $-3,16^{\mathrm{ns}}$ \\
\hline & Pecuária & 4,91 & 4,79 & 4,21 & 3,37 & 4,19 & 5,11 & 4,35 & $-1,21^{\mathrm{ns}}$ \\
\hline & Total & 5,86 & 7,40 & 5,81 & 4,04 & 5,34 & 6,23 & 5,81 & $-2,95^{\mathrm{ns}}$ \\
\hline \multirow{3}{*}{ Mata Norte } & Agrícola & 3,36 & 4,59 & 5,55 & 4,46 & 4,95 & 4,75 & 4,20 & $4,96^{\mathrm{ns}}$ \\
\hline & Pecuária & 2,80 & 2,97 & 2,80 & 2,66 & 4,01 & 4,80 & 3,19 & $10,12 * *$ \\
\hline & Total & 3,13 & 3,41 & 3,12 & 2,95 & 4,26 & 4,79 & 3,48 & $7,82 * *$ \\
\hline \multirow{3}{*}{ Metropolitana } & Agrícola & 10,79 & 14,55 & 13,12 & 18,81 & 4,84 & 5,89 & 12,04 & $-17,05^{\mathrm{ns}}$ \\
\hline & Pecuária & 4,45 & 2,96 & 3,15 & 3,60 & 4,24 & 3,39 & 3,40 & $-0,42^{\mathrm{ns}}$ \\
\hline & Total & 10,46 & 10,70 & 9,60 & 16,18 & 4,72 & 5,08 & 9,98 & $-15,8 * *$ \\
\hline \multirow{3}{*}{ Pernambuco } & Agrícola & 4,26 & 6,62 & 7,18 & 6,35 & 5,30 & 5,04 & 5,32 & $0,14^{\mathrm{ns}}$ \\
\hline & Pecuária & 5,22 & 6,08 & 4,14 & 3,75 & 4,34 & 5,00 & 4,67 & $3,76^{\mathrm{ns}}$ \\
\hline & Total & 4,69 & 6,22 & 4,51 & 4,12 & 4,49 & 5,01 & 4,83 & $-2,10^{\mathrm{ns}}$ \\
\hline
\end{tabular}

ns: Estatisticamente não significativo.

* Estatisticamente significativo a 5\% de probabilidade.

** Estatisticamente significativo a $10 \%$ de probabilidade.

Fonte: Elaborada pelos autores com base em BACEN (2020).

Essa assimetria entre a RD Metropolitana e as demais ocorreu essencialmente pelo valor médio elevado dos contratos agrícolas ( $\mathrm{R} \$ 12.042,42)$, já que a média de valor dos contratos da atividade pecuária não variou tão expressivamente entre as Regiões. Nesse ponto, vale mencionar que os valores médios dos contratos agrícolas no período foram maiores que os da pecuária, com exceção dos financiamentos das RDs Sertão do Araripe, Sertão Central e Agreste Meridional, as Regiões mais representativas na pecuária.

Quanto à evolução dos valores médios totais (Tabela 4), observou-se que diminuíram em 9 das 12 RDs, mas somente na Metropolitana $(-15,8 \%)$, a queda foi significativa. Levando em consideração que os valores médios dos contratos dos estabelecimentos rurais nordestinos, inclusive de Pernambuco, são os menores do país, sinalizou-se que houve pouca alteração do Programa neste sentido, apesar das oscilações mostrarem valores um pouco maiores nos anos de ampliação dos recursos, no período de instituição das linhas especiais. Entre as Regiões que apresentaram aumento nos valores médios foi significativa na RD Agreste Setentrional (8,20\%) e Mata Norte (7,82\%). Em Pernambuco, não houve mudança significativa, indicando estabilidade nos valores médios dos contratos.

No tocante dos valores médios agrícolas, notou-se aumento em 4 RDs e diminuição em 8, sendo significantes apenas o crescimento, ao ano, na RD Agreste Setentrional (6,36\%) e a queda, no Sertão do Pajeú (-7,41\%). No que se referiu aos valores médios dos financiamentos da pecuária, o quadro foi semelhante, com aumento em 4 RDs, sendo significativos nas RDs Agreste Setentrional (10,65\%) e Mata Norte $(10,12 \%)$. Em se tratando do estado de Pernambuco, como todo, houve constância nas médias de valores dos contratos em nas atividades mencionadas, visto que, as alterações não foram estatisticamente significativas.

Com base nessa dinâmica de distribuição dos contratos do Pronaf e nas características dos estabelecimentos familiares por Região (Tabela 5), pôde-se apreender que as RDs Agreste Meridional, Sertão do Araripe e Agreste Central, em que os financiamentos da pecuária foram predominantes, acessaram o maior número de contratos e de volume de recursos do Pronaf, e estiveram entre as Regiões que mais concentraram estabelecimentos familiares. Não obstante, essas RDs apresentaram os menores percentuais de acesso à orientação técnica, o que indicou que recursos mais volumosos do Programa não refletiram em maiores possibilidades de obtenção de informações técnicas, essenciais para a melhoria da produção agropecuária e para a adoção 
de práticas mais rentáveis nos estabelecimentos rurais. Embora o acesso à orientação técnica tenha sido bastante precário em todas as RDs, vale destacar que foi o setor público responsável por $54,6 \%$ do total de orientação recebida nos estabelecimentos.

Tabela 5 - Síntese das características da agricultura familiar e da distribuição dos contratos do Pronaf de 2013 a 2018, nas RDs de Pernambuco.

\begin{tabular}{cccccccc}
\hline RD & $\begin{array}{c}\text { Distrib. } \\
\text { Estab. }\end{array}$ & $\begin{array}{c}\text { Área } \\
\text { Média } \\
\text { (ha) }\end{array}$ & $\begin{array}{c}\text { Média } \\
\text { pessoal } \\
\text { ocupado }\end{array}$ & $\begin{array}{c}\text { Acesso } \\
\text { àientação } \\
\text { técnica }\end{array}$ & $\begin{array}{c}\text { Distrib. } \\
\text { número } \\
\text { contratos } \\
\text { Pronaf }\end{array}$ & $\begin{array}{c}\text { Distrib. } \\
\text { valor } \\
\text { contratos } \\
\text { Pronaf* }\end{array}$ & $\begin{array}{c}\text { Valor médio } \\
\text { contrato } \\
\text { Pronaf } \\
\text { (R\$)* }\end{array}$ \\
\hline Agreste Meridional & $20,5 \%$ & 7,4 & 2,6 & $3,8 \%$ & $19,0 \%$ & $22,3 \%$ & $5.681,01$ \\
\hline Sertão do Araripe & $10,0 \%$ & 16,7 & 2,9 & $4,4 \%$ & $15,6 \%$ & $14,6 \%$ & $4.514,48$ \\
\hline Agreste Central & $14,8 \%$ & 6,0 & 2,2 & $4,4 \%$ & $14,0 \%$ & $14,6 \%$ & $5.040,11$ \\
\hline Sertão do São Francisco & $6,9 \%$ & 20,2 & 2,9 & $14,5 \%$ & $8,6 \%$ & $9,2 \%$ & $5.161,77$ \\
\hline Mata Sul & $6,2 \%$ & 5,2 & 2,4 & $11,8 \%$ & $5,8 \%$ & $7,0 \%$ & $5.808,17$ \\
\hline Sertão do Pajeú & $10,5 \%$ & 11,8 & 2,2 & $6,6 \%$ & $8,0 \%$ & $6,2 \%$ & $3.720,03$ \\
\hline Agreste Setentrional & $9,9 \%$ & 3,4 & 2,2 & $4,9 \%$ & $7,9 \%$ & $5,5 \%$ & $3.375,64$ \\
\hline Sertão Central & $4,2 \%$ & 21,4 & 2,6 & $8,7 \%$ & $4,9 \%$ & $5,3 \%$ & $5.266,95$ \\
\hline Sertão de Itaparica & $3,6 \%$ & 16,7 & 2,9 & $7,5 \%$ & $5,8 \%$ & $5,2 \%$ & $4.375,93$ \\
\hline Mata Norte & $4,6 \%$ & 3,0 & 2,2 & $6,0 \%$ & $5,8 \%$ & $4,2 \%$ & $3.481,38$ \\
\hline Sertão do Moxotó & $6,1 \%$ & 14,3 & 2,6 & $2,9 \%$ & $3,5 \%$ & $3,5 \%$ & $4.906,46$ \\
\hline Metropolitana & $2,6 \%$ & 3,3 & 2,3 & $5,9 \%$ & $1,1 \%$ & $2,3 \%$ & $9.981,45$ \\
\hline
\end{tabular}

*Valor e valor médio deflacionados com base no IGP-DI geral anual, 2018=100.

Fonte: Elaborada pelos autores com base em IBGE (2017) e BACEN (2020).

Atendo-se agora ao outro extremo, isto é, às RDs que menos acessaram ao Pronaf, constatou-se que a Metropolitana e Sertão do Moxotó apresentaram tanto o menor número de contratos como de montante de recursos, porém ocorreram duas situações adversas, a respeito da concentração dos estabelecimentos familiares nessas Regiões. A RD Metropolitana é de fato a menos representativa em número de estabelecimentos familiares, o que justificou em parte uma participação relativamente menor no Programa. No entanto, apresentou o maior valor médio total dos contratos que, inclusive, destoou completamente das demais Regiões, indicando que essas áreas podem concentrar cadeias produtivas mais dinâmicas e os agricultores familiares mais capitalizados.

Já a RD Sertão do Moxotó, que apresentou uma concentração de estabelecimentos familiares intermediária, maior por exemplo que as RDs Mata Norte, Sertão Central e Sertão de Itaparica, participou de menos do total de recursos do Pronaf que elas, o que pode indicar uma dificuldade maior de acesso aos recursos e de refletir na atuação no Programa sua participação na agricultura familiar no estado. No que tange à orientação técnica, que variou entre as Regiões de 2,9\% a 14,5\%, a RD Sertão do Moxotó apresentou o menor percentual, já a Metropolitana, intermediário. Lembrando que, de maneira geral, o acesso à assistência técnica nas RDs é baixo.

As RDs Agreste Setentrional, Sertão do Pajeú e Mata Norte também acessaram proporcionalmente menos recursos do Programa que o percentual de estabelecimentos familiares que concentraram. Além disso, apresentaram os contratos com os menores valores médios do estado e um percentual intermediário de orientação técnica, ainda que bem próximo dos mais baixos, indicando que nestas áreas se concentram os agricultores familiares mais vulneráveis e com menor capacidade de pagamento.

Por fim, verificou-se que as Regiões do Sertão do São Francisco, Mata Sul, Sertão Central e Sertão de Itaparica conseguiram acessar um montante de recursos superior à sua concentração de estabelecimentos rurais. Essas são Regiões que apresentaram as maiores áreas médias, com exceção da Mata Sul, mas que principalmente se destacaram no percentual de recebimento à orientação técnica, principalmente as RDs Sertão do São Francisco e Mata Sul. Essa perspectiva corrobora com a argumentação de Vital e Melo (2015), que analisaram o microcrédito rural em Pernambuco, de que o processo de obtenção do financiamento é lento e envolve primeiramente o acesso às informações e esclarecimento sobre suas vantagens. Assim, as 
percepções positivas dos beneficiários que acessaram ao crédito são responsáveis por disseminar o Programa, ajudando a captar novos agricultores interessados nos financiamentos.

\section{Considerações Finais}

Em Pernambuco, entre 2013 e 2018, o Pronaf financiou predominantemente a pecuária, tanto em termos de número $(75,4 \%)$ como de valor monetário $(72,9 \%)$. Analisando a evolução do Programa no estado, constatou-se uma leve queda anual significativa no número de contratos totais e uma certa constância nos valores monetários totais. Em termos de RD, demonstrouse que no período analisado houve apenas uma com crescimento significativo em número de contratos. No caso dos recursos, notou-se que a diminuição foi concentrada principalmente nas áreas de sertão, indicando uma retração nas áreas mais vulneráveis.

Acerca das diferentes atividades financiadas, notou-se panoramas inversos para a agricultura e a pecuária, em que as quedas anuais nos contratos agrícolas foram bem mais relevantes que os aumentos verificados na pecuária. Isso se deveu à ampliação dos contratos agrícolas no início do período com as linhas emergenciais, o que não se sustentou no decorrer dos outros anos. Em relação aos valores médios totais, observou-se queda pontual na RD Metropolitana, que indicou retração no número e no valor monetário dos contratos mais voluptuosos do Programa relacionados à atividade agrícola. Além disso, houve aumento nas RDS Agreste Setentrional e Mata Norte, em áreas que se dedicam, sobretudo, à pecuária.

Verificou-se também que os valores médios dos contratos agrícolas foram superiores na maioria das RDs e que as oscilações entre 2013 e 2018 foram pontuais, sugerindo que não houve mudanças substanciais. Algo preocupante tendo em vista os contratos com valores extremamente baixos do estado. Pela aferição da TGC por atividade, verificou-se aumento significativo dos contratos agrícolas na RD Agreste Setentrional e uma queda no Sertão do Pajeú; já na pecuária, apresentou-se crescimento nas RDs Agreste Setentrional e na Mata Norte.

Neste contexto, à medida que se analisou a distribuição territorial dos recursos por Região de Desenvolvimento, foi possível constatar disparidades nos acessos ao Pronaf, até mesmo pela heterogeneidade dos grupos familiares e dos diversificados contextos produtivos, econômicos e sociais em que estão inseridos. Por outro lado, precisa-se ponderar que toda essa diversidade esteve e está assentada em uma estrutura agrícola e agrária historicamente desigual que deixou a agricultura familiar à margem no processo de desenvolvimento da agricultura e isso se reflete nas várias restrições que os agricultores enfrentam no desenvolvimento das atividades produtivas e no acesso a políticas públicas, até mesmo as mais direcionadas.

Entretanto, a dinâmica de operacionalização do Programa não mostrou necessariamente se orientar por aspectos de qualificação da agricultura familiar no estado ou seguindo padrões gerais de área, média de pessoal ocupado e obtenção de orientação técnica, apesar de cada um desses aspectos influenciar em menor ou maior grau no processo de desenvolvimento da atividade produtiva, no acesso a informações e na obtenção de financiamentos, em cada uma das Regiões. De toda forma, evidenciou-se que o crédito rural do Pronaf tem foco principal no financiamento de atividades pecuárias se concentrando em Regiões de Desenvolvimento (Agreste Meridional, Sertão do Araripe e Sertão Central) que concentram o maior número de estabelecimentos familiares, quase $50 \%$ do total do estado, e são áreas pobres.

Em contrapartida, essas regiões apresentam os menores percentuais de assistência técnica, explicitando que maiores volumes de financiamento não aparecem nitidamente associados, nessas Regiões, ao acesso à orientação técnica e nem têm propiciado um maior suporte técnico na sua aplicação nos estabelecimentos. Em panorama adverso, outras RDs, principalmente a Sertão do São Francisco e Mata Sul, pareceram viabilizar maior acesso ao Programa associado a maior percentual de orientação técnica, visto que são RDs que conseguiram ter uma participação maior no Pronaf em relação à sua representatividade na agricultura familiar pernambucana.

Logo, considerando que quase metade dos recursos do Programa foram alocados em apenas três RDs, torna-se pertinente o questionamento sobre a aplicação adequada desses recursos, conforme o projeto técnico elaborado como requisito para a 
liberação do financiamento. Afinal, a obtenção do crédito rural é fundamental, mas sem acesso à orientação técnica apropriada que possibilite a alocação eficiente nos estabelecimentos familiares, pouco se avança na diminuição da vulnerabilidade às condições ambientais e no processo de inserção e integração desses pequenos agricultores nas cadeias de comercialização.

Conclui-se, por fim, que o crédito rural disponibilizado por meio do Pronaf é importante para a viabilização das atividades da agricultura familiar, porém, apresenta dificuldades em atender de forma efetiva os grupos mais pobres localizados de forma geral no Nordeste e também em Pernambuco, o que se reflete no baixo número de estabelecimentos que têm acesso ao Programa, na pouca participação no montante dos recursos alocados e nos valores médios exíguos dos contratos. Ao se atentar para o fato de que esses recursos, além de escassos, ainda não são acompanhados, minimamente, por um suporte técnico para sua aplicação e nem associados a outras iniciativas de inserção dos agricultores no mercado, ficam ainda mais notórias as limitações do Pronaf em valorizar a mão de familiar, gerar renda e promover o desenvolvimento rural sustentável nesses locais.

Para estudos posteriores, sugerem-se análises qualitativas e quantitativas sobre o Pronaf, tanto em Pernambuco como em outros estados do Nordeste, aprofundando-se na diversidade intrarregional característica dos grupos da agricultura familiar e na aplicação dos recursos por atividade produtiva e finalidade. De modo a contribuir diretamente para a compreensão e avaliação, contextualizada, dos diferentes fatores que interferem no processo de viabilização do crédito rural nesses estados, que embora contemplem o maior número de agricultores familiares, acessam proporcionalmente o menor volume de recursos.

\section{Agradecimentos}

Os autores agradecem à Coordenação de Aperfeiçoamento de Pessoal de Nível Superior - Brasil (CAPES) pelo apoio na realização dessa pesquisa. Código de Financiamento 001.

\section{Referências}

Aquino, J. R., \& Schneider, S. (2015). O Pronaf e o desenvolvimento rural brasileiro: avanços, contradições e desafios para o futuro. In: Grisa, C., \& Schneider, S. (org.). Políticas públicas de desenvolvimento rural no Brasil (pp. 53-81). Ed. da UFRGS.

Araújo, J. A., \& Vieira Filho, J. E. R. (2018). Análise dos impactos do Pronaf na agricultura do Brasil no período de 2007 a 2016. Texto para discussão, n. 2412. Rio de Janeiro: IPEA.

Banco Central do Brasil - BACEN. (2020). Matriz de Dados do Crédito Rural (MDCR). https://www.bcb.gov.br/estabilidadefinanceira/micrrural.

Barros, G.S.C. (2014). Agricultura e indústria no desenvolvimento brasileiro. In: Buainain, A. M et al. (org.). O mundo rural no Brasil do século 21: a formação de um novo padrão agrário e agrícola (pp. 81-116). Embrapa. https://www.embrapa.br/busca-de-publicacoes/-/publicacao/994073/o-mundo-rural-no-brasil-doseculo-21-a-formacao-de-um-novo-padrao-agrario-e-agricola.

Bianchini, V. (2015). Vinte anos do PRONAF, 1995-2015: avanços e desafios. SAF/MDA.

Buainain, A.M et al. (2014). O tripé da política agrícola brasileira: crédito rural, seguro e Pronaf. In: Buainain, A. M et al (org.). O mundo rural no Brasil do século 21: a formação de um novo padrão agrário e agrícola (pp. 827-864). Embrapa. https://www.embrapa.br/busca-de-publicacoes/-/publicacao/994073/omundo-rural-no-brasil-do-seculo-21-a-formacao-de-um-novo-padrao-agrario-e-agricola.

Brasil (2017). Decreto $n^{\circ}$ 9.064, de 31 de maio de 2017. Dispõe sobre a Unidade Familiar de Produção Agrária, institui o Cadastro Nacional da Agricultura Familiar e regulamenta a Lei n 11.326 , de 24 de julho de 2006, que estabelece as diretrizes para a formulação da Política Nacional da Agricultura Familiar e empreendimentos familiares rurais. http://www.planalto.gov.br/ccivil_03/_ato2015-2018/2017/decreto/d9064.htm.

Brasil (2006). Lei $n^{\circ} 11.326$, de 24 de julho de 2006. Estabelece as diretrizes para a formulação da Política Nacional da Agricultura Familiar e Empreendimentos Familiares Rurais. http://www.planalto.gov.br/ccivil_03/_ato2004-2006/2006/lei/111326.htm.

Buriti, C.O., \& Barbosa, H.A. (2018). Um século de secas: por que as políticas hídricas não transformaram o semiárido brasileiro? Lisboa: Editora Chiado.

Da Silva, D.M.O.B et al. (2017). Pronaf: Uma avaliação da Distribuição Regional dos contratos de crédito e seus impactos sobre o desenvolvimento rural do Nordeste Brasileiro. OKARA: Geografia em debate. 11(2), 376-396. https://periodicos.ufpb.br/index.php/okara/article/view/32694/19031.

Gazolla, M., \& Schneider, S. (2013). Qual "fortalecimento" da agricultura familiar? Uma análise do Pronaf crédito de custeio e investimento no Rio Grande do Sul. Revista de Economia e Sociologia Rural, 51(1), 45-68. https://www.scielo.br/scielo.php?script=sci_arttext\&pid=S0103$20032013000100003 \& \operatorname{lng}=$ en \&nrm=iso.

Guanziroli, C. E. (2007). Pronaf dez anos depois: resultados e perspectivas para o desenvolvimento rural. Rev. Econ. Sociol. Rural, 45 (2), 301328. http://www.scielo.br/scielo.php?script=sci_arttext\&pid=S0103-20032007000200004\&lng=en\&nrm=iso. 
Gujarati, D. (2006). Econometria básica. Elsevier.

Instituto Brasileiro de Geografia e Estatística - IBGE. (2017). Censo agropecuário 2017. https://sidra.ibge.gov.br/pesquisa/censo-agropecuario/censoagropecuario-2017.

Instituto Brasileiro de Geografia e Estatística - IBGE. (2019). Censo agropecuário 2017: Resultados definitivos. IBGE. https://biblioteca.ibge.gov.br/visualizacao/periodicos/3096/agro_2017_resultados_definitivos.pdf.

Matias-Pereira, J. (2010) Manual de metodologia da pesquisa científica. Atlas.

Mattei, L. (2005). Impactos do Pronaf: análise de indicadores. Brasília: Ministério do Desenvolvimento Agrário, Núcleo de Estudos Agrários e Desenvolvimento Rural.

Monteiro, P.A., \& Lemos, J.J. (2019). Desigualdades na distribuição dos recursos do Pronaf entre as regiões brasileiras. Revista de Política Agrícola, ano XXVIII (1), 6-17. https://seer.sede.embrapa.br/index.php/RPA/article/view/1279/pdf.

Pernambuco. (2018). Lei complementar $n^{o} 388$, de 27 de abril de 2018. Regulamenta o disposto no $\S 3^{\circ}$ do art. 25 da Constituição Federal. https://legis.alepe.pe.gov.br/texto.aspx?tiponorma=2\&numero=388\&complemento $=0 \& a n o=2018 \&$ tipo $=\& u r l=$.

Pires, M. J. S. (2013). Contradições em processo: um estudo da estrutura e evolução do Pronaf de 2000 a 2010 . Texto para discussão n. 1914. IPEA.

Pretto, J. M., \& Horn, C. H. (2020). Uma avaliação do Pronaf no período 1995-2018. Colóquio - Revista do Desenvolvimento Regional. 17 (1), 35-49. https://seer.faccat.br/index.php/coloquio/article/view/1577\#: :text=Este\%20artigo\%20apresenta\%20uma\%20avalia\%C3\%A7\%C3\%A3o,da\%20Agricultura\% 20Familiar\%20(PRONAF).

Queiroz, J.F., Lunas, D.A.L., \& Frias, O.A. (2015). Análise do crédito do PRONAF no estado de Goiás no período de 2000-2011. Revista Desenvolvimento Socioeconômico em debate, 1 (2), 5-26. http://periodicos.unesc.net/RDSD/article/view/2394.

Sampaio, Y, \& Vital, T. (2020, agosto). Agricultura familiar em Pernambuco: o que diz o censo agropecuário de 2017. Revista Econômica do Nordeste, v. 51, 155-171. https://www.bnb.gov.br/documents/80223/8054629/E_1263.pdf/84ffff26-e71b-6df3-b6d6-bfc9dc4983ad.

Schneider S., Mattei, L. \& Cazella, A. A. (2004). Histórico, caracterização e dinâmica recente do Pronaf - Programa Nacional de Fortalecimento da Agricultura Familiar. In: Schneider, S., Kunrath Silva, M., \& Moruzzi Marques, P. E. (orgs.). Políticas públicas e participação social no Brasil rural (pp. 21-50). Editora da UFRGS

Sigaud, L., \& L'estoile, B. (org.). (2006). Ocupações de terra e transformações sociais: uma experiência de etnografia coletiva. Editora FGV.

Souza, P.M., \& Barbé, L.C. (2014). Desigualdades regionais na distribuição dos financiamentos do Pronaf: uma análise do período de 1998 a 2012. Revista Econômica do Nordeste, 45, 31-43. https://www.bnb.gov.br/documents/80223/205365/ren_2014_3_paulo_v2.pdf/abff8f93-7555-498e-8dba-57d6fbf63567.

Vital, T. W., \& Melo, L.M. (2010). Comercialização agrícola na pequena produção familiar da zona da mata de Pernambuco: novos subsídios para o planejamento. In: Academia Pernambucana de Ciência Agronômica, vol. 7, Anais [...]. http://www.journals.ufrpe.br/index.php/apca/article/view/123.

Vital, T. W., \& Melo, A. (2015). O agroamigo em Pernambuco: alguns resultados. Revista Econômica do Nordeste, 46, 123-138. https://www.bnb.gov.br/documents/80223/800344/Art8_REN_ESP_2015.pdf/f4d960ec-9348-4b41-a42f-2a3b14b3cf7a 